\title{
COMPARISON OF ARC EROSIVE AND LASER BEAM TRIMMING OF THIN FILM RESISTORS
}

\author{
Zs. ILLYEFALVI-VITÉZ \\ Department of Electronics Technology, Technical University of Budapest, H-1521 Budapest, Hungary
}

(Received June 10, 1977)

\begin{abstract}
The physical processes of arc erosive micromachining and the influence of trimming on the parameters of resistors have been examined, and thin film resistors without trimming are compared with those trimmed by arc erosion and laser beam machining.

In the paper a theoretical model for arc erosion of thin films is proposed. The optimal conditions of arc erosive trimming are determined. The shape of the cuts are recorded and examined. The applicability of arc erosive trimming with respect to stability is proved. A measuring method is introduced for resistors trimmed by arc erosion using a direct current generator.
\end{abstract}

\section{ARC EROSIVE MICROENGRAVING OF THIN FILMS}

The arc erosive microengraving of thin films is widely used in Hungary for trimming resistors in hybrid microcircuits. For this reason, the physical processes of arc erosive micromachining and the influence of trimming on the parameters of resistors have been examined, and thin film resistors without trimming are compared with those trimmed by arc erosion and laser beam machining.

To produce arc erosive micromachining a voltage difference is needed between the film and the machining stylus sliding on the substrate (Figure 1). When the stylus reaches the edge of the film a very

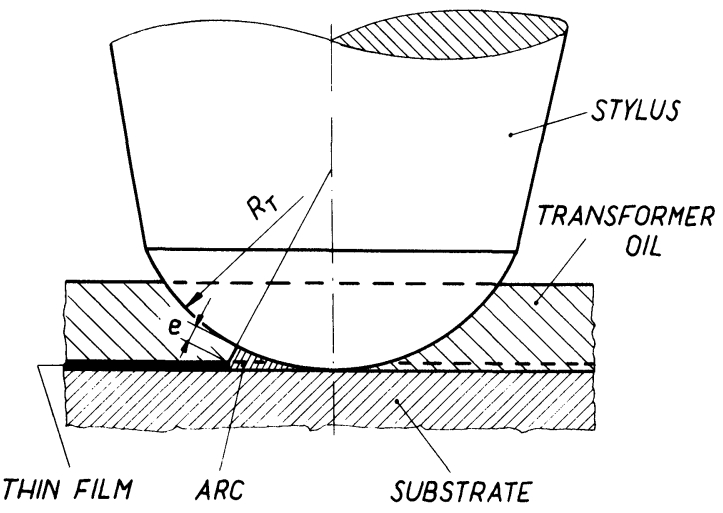

FIGURE 1 Arrangement for arc erosive trimming. high current density is resulted, the temperature increases, a small region of the film evaporates and the metallic connection breaks. In the narrow gap the evaporated atoms are ionized by the high temperature and electric field, and the current is maintained by an electric arc. As a consequence of further evaporation the width of the gap and the length of the arc increases until the arc is quenched. This process is similar to that formed between separated contacts but the current of the arc between the thin film and the stylus is much lower and the quenching length is much shorter than the usual value between low voltage contacts. So the characteristic of the low voltage arc can be examined in a little known zone of low currents and short lengths by arc engraving of thin films (Figure 2).

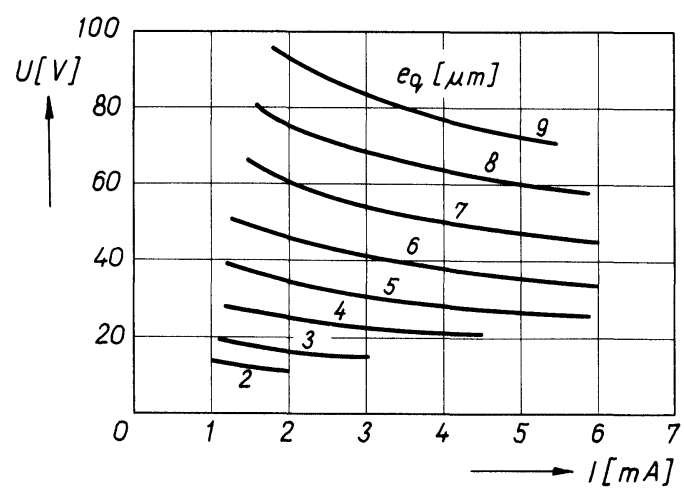

FIGURE 2 The characteristics of erosive arc. 
On the basis of the theoretical formula suggested by Holm ${ }^{1}$ and Ives, ${ }^{2}$ the measured characteristics of the erosive arc were empirically approximated by the following function:

$$
V=V_{0}+\frac{\left(e-e_{0}\right)^{2}}{b} \cdot \frac{\left(e-e_{0}\right)^{2}}{b^{2} c I},
$$

where $V$ is the voltage, $I$ is the current, $e$ is the length of the arc and $e_{0}$ is the "shortest" length of the arc. $V_{0}, b$ and $c$ are constants determined by the material of the thin film, that of the substrate, stylus and of the medium around the arc. They are also determined by mechanical parameters, such as the radius of the stylus, the force compressing the stylus onto the substrate, etc.

\section{OPTIMAL CONDITIONS FOR ARC ENGRAVING}

The width of the cut is essentially determined by the quenching length of the arc and the mechanical properties of the stylus. It has been found that optimal cut is obtained under the following conditions:

1) The stylus is made of a metal which is less volatile than the material of the film (e.g. tungsten, nickel or stainless steel for nickel-chromium or gold films).

2) The film is machined in a liquid having high thermal conduction and specific resistivity (e.g. transformer oil).

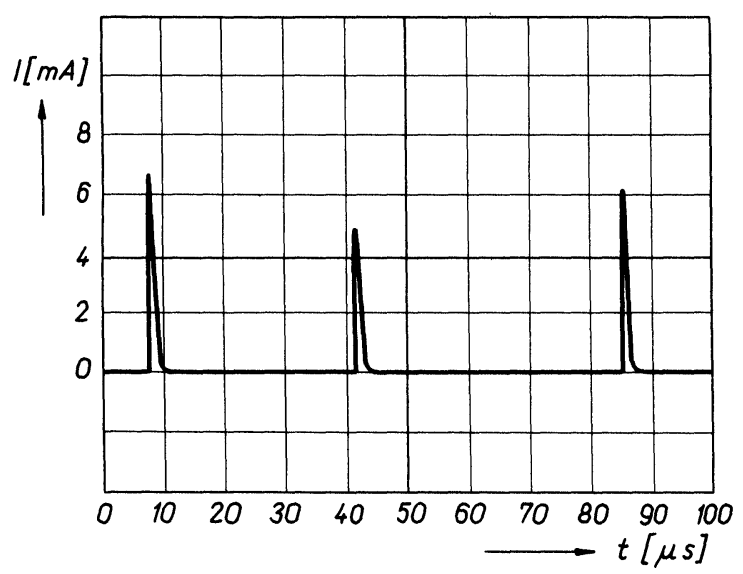

FIGURE 3 The erosive current vs. time on the display of Tektronix Storage Oscilloscope.
3) The electric source is a constant current pulse generator or a simple direct current generator. In the case of pulse generator the resistance can be measured during the pulse intervals.

In the case of d.c. generator it is found that the erosive current is pulsed with low duty cycle (Figure $3)$. At low speeds the average value of this pulsedform erosive current $\left(I_{E}\right)$ is much lower than the measuring current $\left(I_{M}\right)$ and it has practically no influence on the accuracy of the measurement. Especially small is the influence of the erosive current, if the circuit shown in Figure 4 is used and the resistance $R_{E}$ between the engraving stylus and the connection is much smaller than the total resistance $R^{3}$

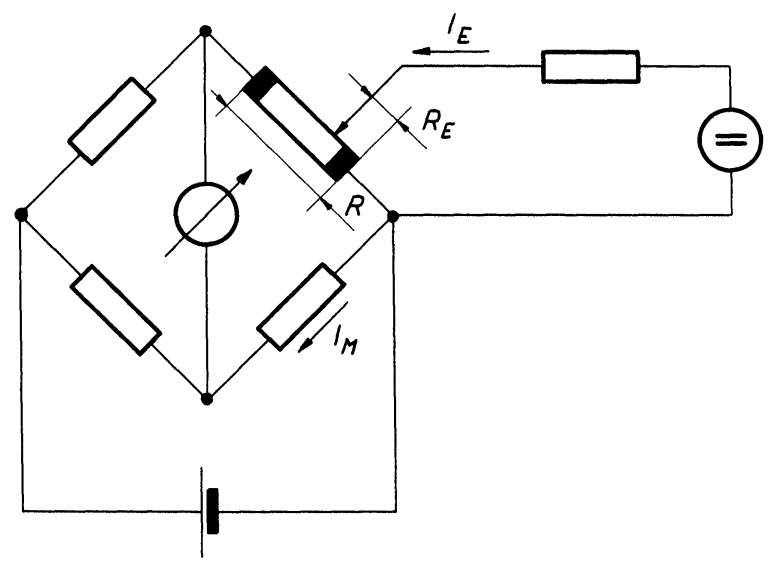

FIGURE 4 Circuit for active trimming.

\section{SAMPLES}

There are two important conditions for the applicability of any trimming method by microengraving:

1) Suitable insulating resistance of the cut.

2) Negligible change in the electrical parameters of the resistive thin film remained on the substrate along the cut.

The tests were done in accordance with these aspects. The samples were evaporated $\mathrm{Ni}-\mathrm{Cr}$ thin resistive films with square resistance of $200 \mathrm{ohms}$. The resistors were formed by sublimation of a wire through bimetal masks. Right after evaporation these resistors had relatively high negative temperature coefficients $\left(T C_{R}\right)$. The structure of the film was ordered by heat treatment. This resulted in a decrease 


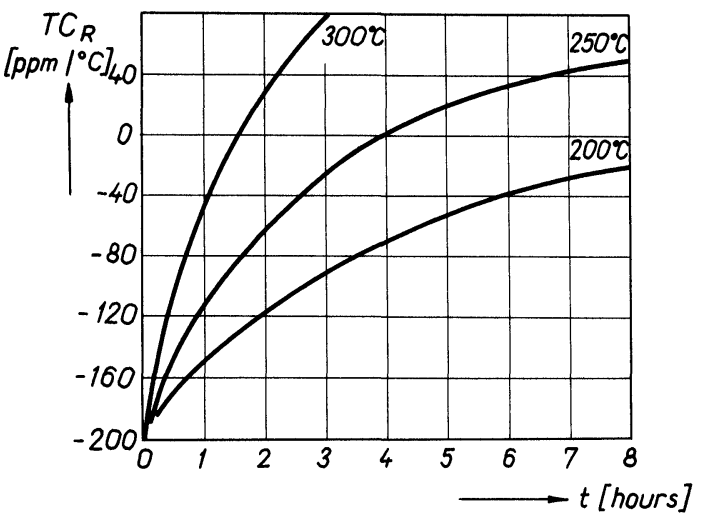

FIGURE $5 T C_{R}$ of $\mathrm{Ni}-\mathrm{Cr}$ thin film vs. heat treatment.

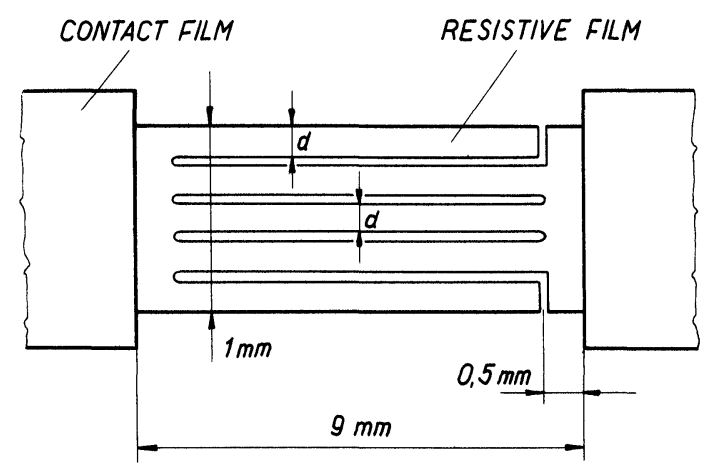

FIGURE 7 Pattern for the determination of the heat effected zone.
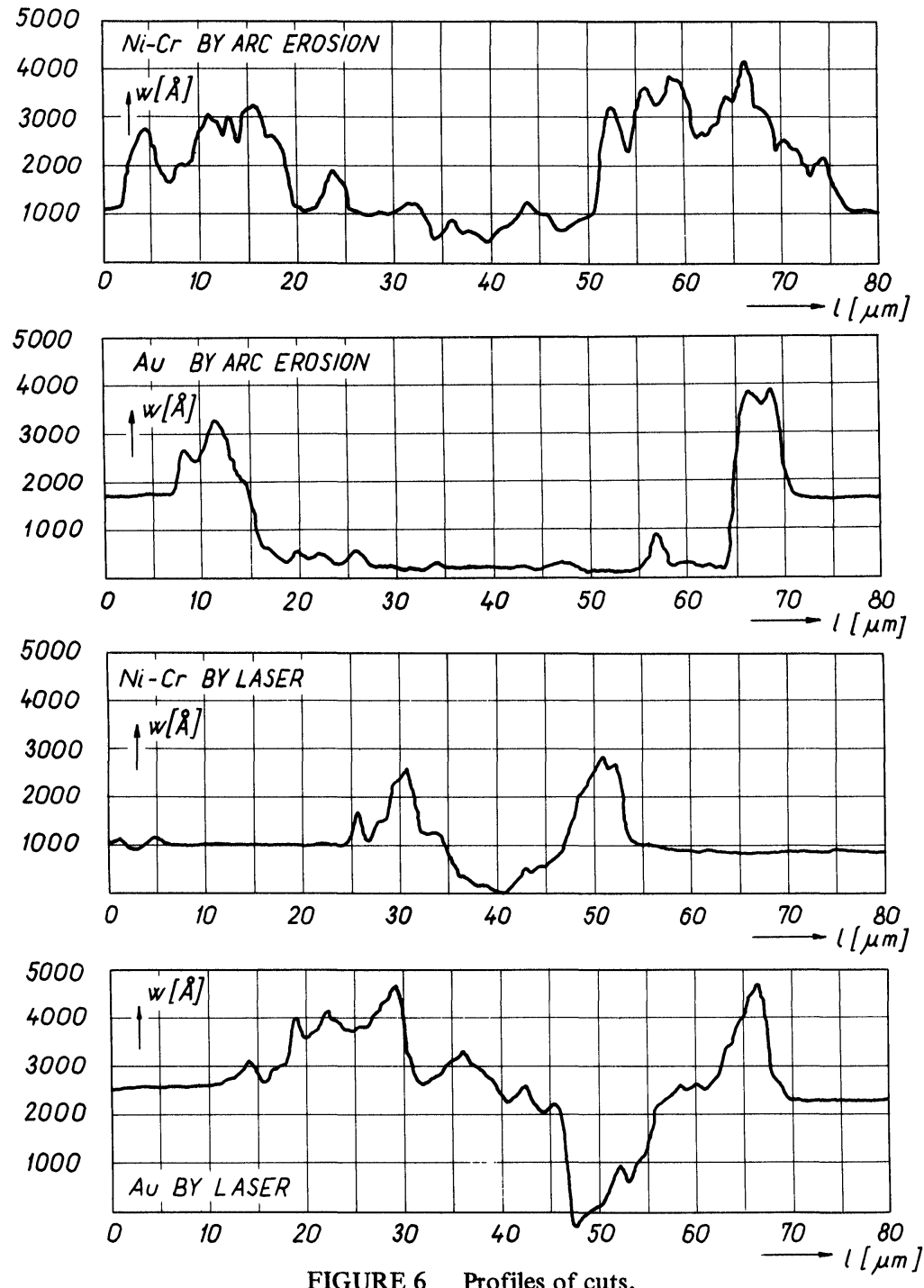
of the specific resistivity and in a change of the temperature coefficient $\left(T C_{R}\right)$ in the positive direction (Figure 5). The $T C_{R}$ of the samples heat treated at $250^{\circ} \mathrm{C}$ during 2 hours were $-60 \mathrm{ppm} /{ }^{\circ} \mathrm{C}$. By suitable heat treatment $\pm 10 \mathrm{ppm} /{ }^{\circ} \mathrm{C} T C_{R}$ could be obtained. The stability of the resistors was typically $-50 \mathrm{ppm}$ to -100 ppm within the limits $\pm 150 \mathrm{ppm}$ under $0,25 \mathrm{~W} / \mathrm{cm}^{2}$ load, at $70^{\circ} \mathrm{C}$ during 1,000 hours.

For contacts gold film of approximately $1500 \AA$ width was used, sandwiched with a thin $\mathrm{Ni}-\mathrm{Cr}$ film to improve adhesion of the gold. The ability of micromachining of this contact film was also examined.

The resistive thin film was engraved by a tungsten stylus with a radius of $10 \mu \mathrm{m}$ connected to $60 \mathrm{~V}$ d.c. The current was limited to $8 \mathrm{~mA}$. The machining voltage of the contact film was $3 \mathrm{~V}$ with the maximal current of $100 \mathrm{~mA}$. In both cases arc engraving took place under transformer oil.

In order to compare arc engraving with laser beam trimming, the same type films were machined using the equipment Laser Optronic 486 L of REMIX Electronic Components Manufacturing Company. The equipment worked in Q-switched mode, with the frequency $1 \mathrm{kHz}$ and the pulse width $0,4 \mu \mathrm{s}$. The power of the laser beam in continuous wave mode was $0,5 \mathrm{~W}$. A cutting velocity of $2 \mathrm{~mm} / \mathrm{s}$ was chosen.

\section{RESULTS}

The insulating resistance of the cut was measured on samples with thin resistive lines of $2 \mathrm{~mm}$ width engraved across. By both methods (arc erosion and laser cut) and on both films ( $\mathrm{Ni}-\mathrm{Cr}$ and $\mathrm{Au})$ the insulating resistance was found greater than $50 \times 10^{12}$ ohms. This value is suitable for the majority of applications.

The shape of the cuts were recorded by the equipment Talystep (Figure 6). The results are the following:

1) The depth of the arc erosive cut is about the same as the thickness of the film. The bottom of the cut is roughened. The depth of the laser beam cut is much greater than the thickness, i.e. the substrate is also damaged.

2) In all cases significant amount of mass is built up on the edge along the cut. The area of the cross section of this built up mass is larger than that of the cut because of its looser and oxidized structure.

3) The laser beam cuts are narrower $(20 \mu \mathrm{m}$ to $25 \mu \mathrm{m})$ than that made by arc erosion $(40 \mu \mathrm{m}$ to $45 \mu \mathrm{m})$.

It is proved by electron probe microanalysis that the arc erosive microengraving mostly clears the

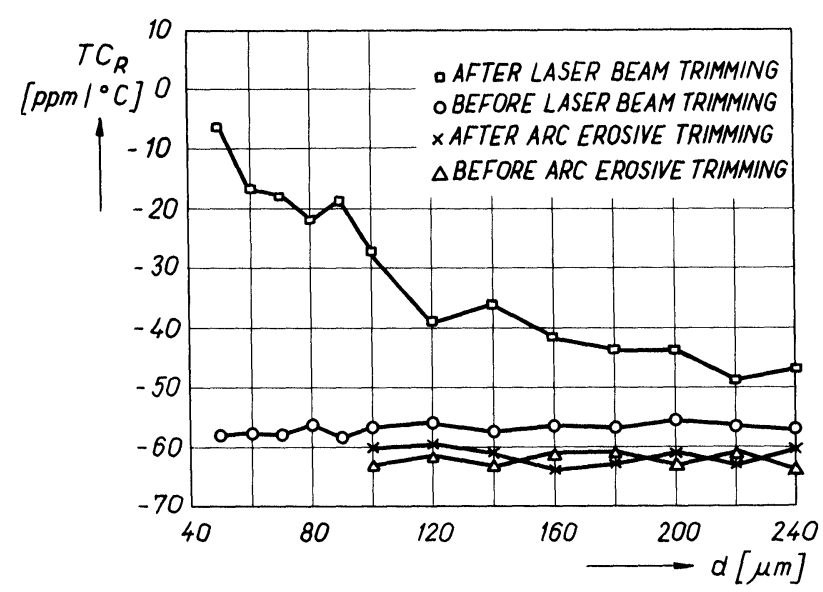

FIGURE 8 The influence of trimming on the $T C_{R}$.

film material away from the cut. After the machining of the gold contact film with the $\mathrm{Ni}-\mathrm{Cr}$ underlayer chromium remains back in the cut and its amount is negligible. In the case of $\mathrm{Ni}-\mathrm{Cr}$ resistive film the result is slightly different from this. $\mathrm{The} \mathrm{Ni}-\mathrm{Cr}$ material remains back in the cut in about $25 \%$, but in the form of separated islands and for this reason it has no influence on the insulating resistance. In the cut the roughness of the bottom shows the existence of islands too.

The influence of the cut on the electrical parameters of the film was examined by the change of $T C_{R}$ and the stability of the resistors. The samples were made by cutting parallel lines with different distances (Figure 7). As shown in Figure 8 the laser beam cutting resulted in a great change of the temperature coefficient. The same change would have been caused, if the film had been heat treated at $250^{\circ} \mathrm{C}$ during further 2 hours. From the break of the curve the width of the heat effected zone is found to be $60 \mu \mathrm{m}$ to $70 \mu \mathrm{m}$. The arc erosive engraving did not cause any change of the $T C_{R}$. The character and value of stability of the resistors formed by arc engraving were not different from those of the resistors without trimming $(-50 \mathrm{ppm}$ to $-100 \mathrm{ppm}$ change caused by $0,25 \mathrm{~W} / \mathrm{cm}^{2}$ load at $70^{\circ} \mathrm{C}$ during 1,000 hours). The stability of the resistors machined by laser beam were slightly worse, the change of resistance was between the limits \pm 200 ppm.

\section{CONCLUSIONS}

1) The applicability of arc erosive trimming with respect to stability has been proved. The heat 
effected zone along the cut is found much narrower than that along the laser beam cut.

2) The line width of the cut obtained by arc erosion is wider than that of the laser beam cut, so the arc erosive method is worse in the viewpoint of miniaturization.

3) The electrical properties of the cut have been improved by finding optimal conditions for arc erosion.

4) A circuit is suggested for active resistance measurement during trimming.

\section{REFERENCES}

1. R. Holm, Electric contacts, Springer Verlag, Berlin, Heidelberg, New York, 1967.

2. H. E. Ives, Minimal length arc characteristics, J. Franklin Inst., 198 (1924), 437.

3. J. Klose and G. Priebsch: Funkenerosive bearbeitung von dünnen, aufgedampften wiederstandsschichten. Hermsdorfer Technische Mitteilungen, 15 (1975), 41. 

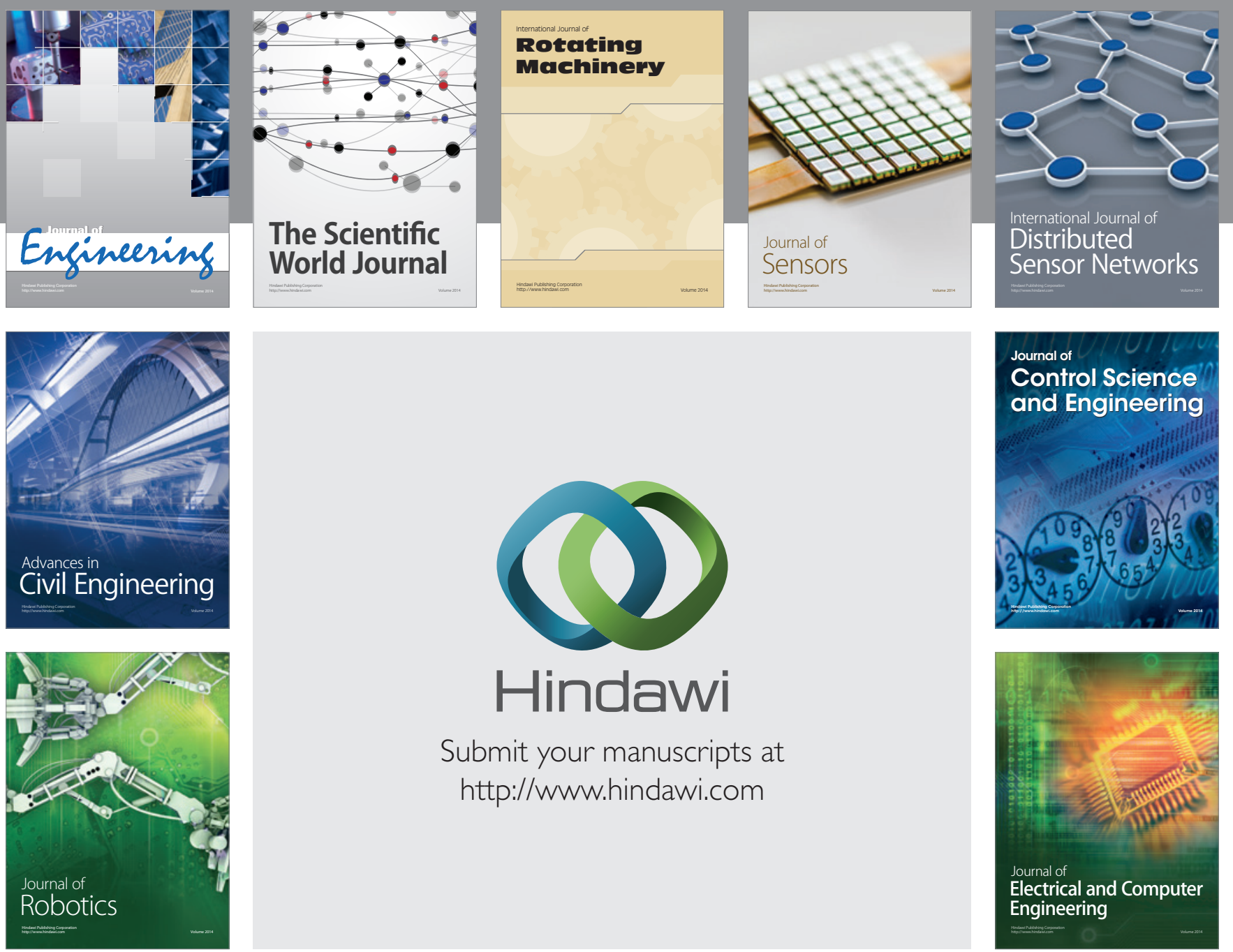

Submit your manuscripts at

http://www.hindawi.com
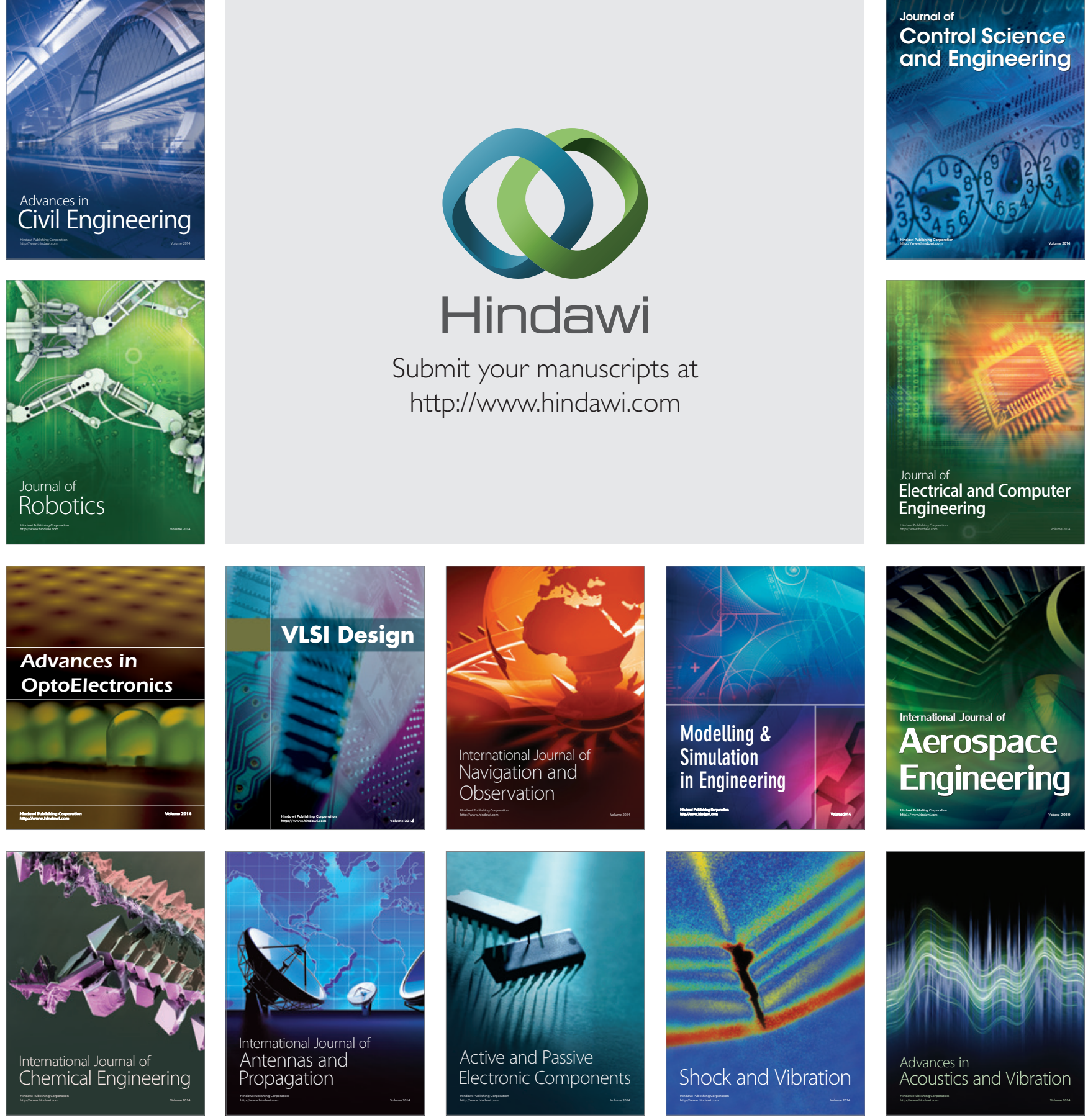